\title{
Interview with Dr Crystal Abidin
}

\author{
KATE STUART, Bangor University \\ EOIN MURRAY, Bangor University
}

Dr Crystal Abidin is a digital anthropologist and ethnographer who examines internet culture, based at Curtin University in Western Australia as a Senior Research Fellow and ARC DECRA fellow in Internet Studies. Her current research focuses on influencer cultures, online visibility, and social media pop cultures, especially in East Asia and the Asia Pacific, reflecting also on life as an anthropologist whose work traverses both online and physical spaces and relationships. In her visit to Bangor as a keynote speaker for the Evolution of Media MeCCSA PGN conference, Dr Crystal discussed one of her more recent projects about vulnerable communities on tumblr, exploring the evolution of culture, practice, and her research within this space.

- You describe yourself as an anthropologist and ethnographer of digital cultures and your research stretches from commercial blogging to your recent book, Instagram: Visual Social Media Cultures with Associate Professor Tama Lever and Dr Tim Highfield. What would you say drew you to research digital cultures and internet studies?

- I guess I have two answers: one is personal, one is more political. I'll start with the personal story. I am born of a generation and in a country that was prepared to groom cohorts of citizens to be extremely IT savvy, so encountering digital culture, the internet, the rise of technology was like a second nature to me, like a fish to water. We began to learn to type, if I'm not wrong, maybe in Kindergarten at age six, and even in primary school we got to learn to organise our fingers along the keyboard and monitor our typing speeds. So as part of a whole national and generational culture in my upbringing, being 'extremely online' was very normal. When I encountered internet culture as a young adult or when moving into my undergraduate studies and developing my academic career, it was a natural progression that the thing that I enjoyed growing up with also became the thing that I enjoyed working on professionally. Many of us have work lives and then like, secretly embarrassing behind-thescenes recreational lives-I brought both of these worlds together and I enjoy making analyses and making deeper meaning out of the things I enjoy, vice versa enjoying my work as well.

Also, since there are probably going to be junior scholars reading this interview, I think a word of caution is due: Everyone always says if you enjoy your work it's not going to feel like work. Now that is a lie! It's just going to feel like everything is work and we have to be 
extra careful about policing our work/life boundaries and ensuring that our wellbeing is taken care of. In my case, one of the gripes that I always put out to the universe is that when I'm not working and using social media recreationally, I always feel compelled to still have my work brain on in the background, or worse, at times feel pressured by others to be working all the time. To combat this, I decided to set up boundaries and guidelines for myself. I've got separate accounts for secretly closeted embarrassing fandoms, my various interests, and my work and professional front. I also set specific times where I am online for work versus being online for leisure. I've got colleagues who are really great and wellversed in code-switching, so we can be on a chat stream talking about work, but if it's on a weekend or a holiday we may use the exact same chat stream to catch up but with a mutual understanding that if our discussion evolves into more serious work, then these can wait for another time and context. All of these choices are now second nature to me. They were the practices I had studied, the habits that I practiced, and now the ethos that I maintain for my own sanity. I want to be clear that as much as I love my research, academia is my job and being an academic is not my master status or my entire identity. It is important to preserve and grow these other facets of oneself.

The political reason for a lot of my work being focused on internet culture, and more specifically a Global South perspective to internet cultures, is that it's very easy for us to run with the adage that the internet is global - it has allowed us to reach all corners of the world, we're basically borderless, that everyone now has equal access, you know, that 'big tech democratic utopian' idea-but yet we also know that for the everyday person, our individual experiences of the internet can be vastly different dependent on your geolocated accessibility, government and state gatekeeping, ISP and server preferences, platform norms, digital cultures, and the like. There are machine and human conditions that factor into play, ranking and mapping and delivering information to each of us differently. I wanted to focus more on the socio-cultural aspect of this internet experience.

Another political reason for wanting to study internet culture is to publicise the plurality internet cultures, to shift away from Anglo-centric discourses, and to push back against ethnocentricism. In much of the research on influencer cultures, there are the unspoken, unmarked, normative or mainstream perceptions of how this world works that usually draw on American phenomena and examples. And in the difficult terrain of academic publishing, it is not uncommon for many non-US focused scholars who study on other cultures to be asked to qualify our choice of scope, sampling, research decisions, and the like. I hope that as more of us focus on the diversity of influencer cultures and online visibility around the world, we can slowly but surely change this type of academic gatekeeping. I would like to contribute to building more of this sort of research. So yeah, I quite enjoy being an ethnographer on the internet-it's a bit like being a Mars Rover on an expedition discovering new things, and then trying to scientifically make sense of them, by 
collaborating with other people who may also encounter these new things, by building relationships and listening to people who are so-called "native" to these spaces, to make sense of these phenomena through social scientific modes of thinking..

- Would you say your practice has evolved as you've moved forward from your early days as a researcher to where you are now?

- This is a very strange question for me to answer, because I graduated less than four years ago so when you say early days, it feels like all my days were my early days - but I get what you're trying to say. I have been studying influencer cultures since my undergraduate research days in 2008. The internet moves quickly. There is a lot of research on the concept of 'internet time' that is compressed, accelerated, linked, anomic, et cetera. Likewise, research practices that develop around the internet-changing platforms, changing rules, changing norms, moralities - also are very accelerated. I would say, in terms of my overall politic, strategically focusing on East Asian and Asia Pacific influencer cultures and from here developing theories and concepts that can be mappable and have far-ranging use value is still my main bread and butter. I think, in my earlier postgraduate years, when I discovered that so much effort was needed to communicate the 'Other', I would just air my frustrations and leave it at that. For instance, why is it that when I submit a journal article, the reviewer or editor comes back with feedback like 'Great article, great title, but in your title can you please add in the country you are looking at?'. And there I was recalling the numerous other studies I read throughout my schooling years, often based on a convenient sample of college students in the, and how none of these were 'marked' but instead taken as a unspoken 'standard'. But as an Early Career Researcher now, I think I've got a little bit more experience, mentorship, and resources to do something about this. For instance, curating edited collections and special issues, bringing resources to events that I specifically want to shape in order to make visible and amplify some research or researchers over others, giving more voice and access to good work that is struggling to register on people's radars, working closely with junior scholars around the world who may struggle with conveying their very smart thoughts in the format of an English-language journal article and spending time to assist them with translations. Much of this is unseen labour, but I have learnt from some good mentors and role models that those of us who have resources and capacity should work to develop or even just signal boost such underrepresented scholarship.

I hope that if you ask me this question again a few years down the road as a Mid-Career Scholar, I will be able to exhibit more action and more leadership in this area. What has remained consistent though, I think, is the importance to maintain a low intensity of anger or frustration with the state of things, to be used as a motivating force to go and do something productive about the situation. I do this for myself by writing very honest confessions and 
thoughts in various online and paper diaries, and periodically review how I have processed these feelings and what has changed since then.

In terms of the content of my research, my very, very earliest research started in the country where I grew up, which is Singapore, and then-by virtue of my migration, personal interests, education, resources, access - expanded to South East Asia, Australia, the Nordic, and East Asia. I now consider my work broadly looking at internet cultures in the Asia Pacific region. I have also gotten to experience various disciplines from my positions at different departments and universities, but still primarily consider myself an anthropologist of digital and media cultures.

- So, you've kind of touched on this already, but what attracts you to examine a particular aspect of the cultures you look at? Are they groups you've already encountered through your online research self or personal self, or do you choose topics that you think is worth exploring and delving into that part of digital culture?

- I think both. All good anthropologists will never be able to completely divest themselvestheir research selves, if there is such a thing as that-from their personal selves. In fact, it makes you a good anthropologist to be able to draw on your own experiences, your own perception of the world, and to use your body as the canvas or a mediator for understanding people in a cultural context you are wanting to study. And to understand other people, you need to hone that inter-personal skill. Even if you are not one for small talk or interacting with strangers, sometimes you need to learn to develop a research persona to do this work well, so there will definitely be an investment of a very deep, personal side of yourself in your work. The extent of this is probably something you can control or decide, based on your project, politics, and preferences though.

To answer your question in brief, many of the projects focus on phenomena that I'm already interested in and want to pursue more analytically. Many of them are issues that I may have chanced upon and do not yet understand, maybe because I am not the target demographic, but want to invest time to study systematically. There are others, especially of late, that are time-specific urgent events that require some sort of research intervention or archival work, and if I feel that I am best placed to do it - whether it's because it's already connected to my work, or that I'm part of a privileged minority to observe this phenomenon in real time-I go and do it. So, I guess I have three different types of research pursuits, and always have multiple projects going on in each of these streams.

For example, I spent some time interviewing Singaporean punk rockers in the underground music scene. Across the age spectrum and genders, most of them were ethnically Malay. Now, I'm part-Malay myself, but my skin tone and appearance may not convey this 
evidently, so many of my Malay punk informants may perceive me with a little bit of otherness and are extra welcoming towards me. This means that when I ask them very basic questions that I probably already know the answers to, they may be more than willing to guide me through like a wanderer, and explain to me things that they would otherwise have assumed that I would know. As a good anthropologist and ethnographer, you know you've got all these tools. You don't use them to deceive people, but rather you rearrange yourself and your interactions to get the best ethnographic data, work very closely with your informants, and then make sense of this for your research.

- You refer to these different roles-hats, almost-that you can wear as an anthropologist in your recent article "Somewhere Between Here and There", and you also talked about the genuine friendships that you can cultivate in this research experience. How do you find yourself navigating that, as this would be blending your researcher self with your personal self a lot more closely?

- There are a lot of hits and misses, so just because you attempt, or have the desire to cultivate a work relationship into a sincere friendship doesn't mean it always happens-it has to be reciprocal. Sometimes it's not for not wanting, sometimes maybe for mental health, or for work/life balance. As a researcher I can also choose limitations on who and what can crossover into my personal life as a deep and genuine friendship. But I think the virtue of being an ethnographer or an anthropologist, especially if you work long-term with a community of people, is that you want to be someone who gives back to the community. You don't want to be an extractor who continually goes back, takes from them, then go away and publish things without any reciprocity. Even if your work does not call for it, or if your paycheck does not depend on it, I think it's a personal ethic and choice to return and sow that back into that space if you have the resources and capacity to do so.

Many of the friendships I build from fieldwork formed organically because of our personalities or ethos or interests. Others were born out of adhoc moments like crises. Say if someone was in a difficult situation and I happened to be available to assist, these types of co-shared struggles can help people to bond and find friendships in the midst of troubles. Still some other friendships were more intentional, for instance, knowing that I needed to have a good relationship with a specific gatekeeper in order to gain more understanding of their milieu.

I think that the positionality you choose to adopt in the field can also sometimes be timespecific. For example, having looked at internet celebrities and influencers since 2008, when I catch up with my old informants now, some of them laugh and joke about how we've literally grown up together and are on our way to growing old! We met when we were in university, when I first started my undergraduate projects with them, and many of them are 
now married and birthing children, so it's be nice to have these 'girl time' catch-ups about the rites of passage that we go through.

- With building those friendships, particularly around some of the serious topics you've looked at (grief, cyberbullying, et cetera), how do you separate yourself and protect yourself in exploring these topics and relationships? What do you do for self-care?

- I don't know if research projects ever have an expiration date, or if you can truly complete something, especially if they are longitudinal anthropological studies. I supposed that logistically, some projects may have an end date - say if you were commissioned to work on something, completed the research, and submitted the report to your sponsors. But if you're developing a field of research, I don't think you ever stop thinking about how to improve and mature your work. It can be that you come upon something in the very early years of your study, only to continuously revisit, redevelop, extend, and follow up on it through the years. Likewise, with my informants, I often follow up with them over the years, whether for ongoing research projects or because I valued our time together and want to sustain our friendship. I like to think that we dip in and out of projects with different intensities across our research careers.

There are some projects that I entered into specifically because of my personal experiences. I started research young people and online grief shortly after I had lost my younger sister to cancer. When Carissa passed away, many of her friends in their late teens and early twenties were writing instant messages, emails, hand letters and going 'Can you not delete her account on Facebook? Can you please print all the photos we have? Can you not delete her cellphone number? Can you maintain this, can you not-'. While these were not my immediate concerns as I was busy tending to post-death paperwork and sorting out my sister's belongings, the intense emotions and volumes of such correspondence clearly indicated that such digital connections were very important to these young people. At that time I was also beginning to befriend many of my sister's friends, in part because our commiseration brought me some comfort, and in part because I felt a sense of duty as a 'big sister' to ensure that they were doing okay.

After a few weeks, I wanted to document and study these young people's experiences of grief more systematically, and asked a small group of them if they would be willing to chat with me in my capacity as a researcher. With the support of a small NGO and a community service, I worked on this pilot study and channeled my grieving into research on grief. This wasn't because I felt pressured to be academically productive, but rather than I needed to create this busy-ness for myself as a meaningful distraction. And while this carried me through the difficult time, after a while it began to feel heavy. By the time when my first chapter on this project was published, I was in a very bad place and did not even page 
through the book to read my writing. When I eventually found the headspace to reenter this project, I continued with interviews. Eventually, I saw how this side project 'for the heart' also connected to my older work on grief tributes on viral Instagram hashtags. I have since taken a break on this specific project, but will return to it in the future.

- Thank you so much for sharing that with us - there's obviously a lot there that can apply to any area of research, as we as researchers so often get personally invested in our projects and struggle to work out where to go from there. To round up, you've looked at so much in-as you say-quite a short time as a researcher, but what do you think you want to explore next? Are there particular platforms you want to look at, or where do you want to go from here? You've obviously got a new book coming soon?

- I do. My fourth book is being published as an edited collection of chapters around June this year, looking at bodies on social media. My fifth one is being co-authored with my colleagues and also very good friends, Katrin Tiidenberg and Natalie Hendry, looking at tumblr - I presented some snippets of this in Bangor. Following this, my next two soleauthored books are extremely precious to me, looking at my longitudinal anthropological work on the origins, development, and cultures of internet celebrity in Singapore and the region. One focuses on online shopping in the form of blogshops, and the other on influencer cultures.

I have had the privilege and experience of having my work profile by some reporters, and many of them tend to end our interviews with the question you just posed: 'What are you going to do next? Which platform will you look at? What's new?'. This assumes that we tend to prize novelty above everything else, and as an internet studies scholar, I cannot deny that there is an ongoing pressure to always be up-to-date and to keen an eye on what's on the horizon. It is part of our jobs to make sense of these new phenomena, to historicize, contextualise and analyse them, to find patterns and question systems, and look for circumventions and subversions and creative appropriations. You know, when we told our friends that we were writing book on tumblr, some of them mused: 'But why? Isn't tumblr like, dead?'. But just because platforms lose their mainstream popularity and media hyperattention does not mean they no longer function for those who stayed; there are still values and meanings and lessons to glean.

These days, most of my research still looks at the broad umbrella of internet pop culture. This comprises anything from celebrities, to influencers, to memes, virality, emoji, et cetera, but my specific slant is always to look at minority groups, subversive appropriations, user agency. For instance: What kind of communities thrive under the radar? What kind of practices are elaborated and expanded on when you have always needed to thrive under the radar, when you've either struggled to be seen by people or the algorithm, or struggled to be 
unseen so that you can just glide and remain there? Such visibility techniques and what it can be used for are the basis of my research and my work.

I'm also working very hard on expanding my language repertoire, in part to fulfill a childhood dream of being competent in many languages, and in part to be a better anthropologist. I hope that in addition to working with my local research teams and field assistants, I will eventually be able to understand East Asian cultures a little bit more thoroughly with the intimacy of shared language. Throughout my fieldwork, I meet a lot of informants who appreciate this effort. When I stuff up with grammar or vocabulary, they are always kind and encouraging. These displays of affirmation are very precious to me, and it makes me want to work harder to be a better researcher when I connect with people in my research fields.

- Thank you so much for speaking to us, once again, and we're looking forward to having this interview in the Networking Knowledge journal to, as you say, highlight a more global perspective.

- For sure! And I'm suddenly thinking again, of our walk to take pictures [in Bangor] of that very elaborate university emblem you have on that brick wall [outside of the main university building]. We were asking Eoin how to pronounce his name [Eoin being the Irish variant of the more familiar Welsh and English name, Owen], and you gave us a mini-lecture on how it's very complicated to be Scottish, and Irish, and English in your part of the world. So likewise, right - there are just so many Englishes, even if we are reading the same script, and MeCCSA is probably a really good avenue to tease that out. Because, even scholars like me or my Asia-based colleagues are sometimes guilty of essentialising and saying 'The West', or 'older White scholars', but there is not one monolithic 'West' and so many types of 'White'. Inter-cultural and inter-regional work is very important, and I would love to watch the MeCCSA network birth more research in these areas.

- [Eoin] - I know my father would love that, because as we were growing up he often liked to tell me about growing up as an Irishman in Belfast during the Troubles period. Again, it was predominantly white, but there was such a cultural break that if you were considered Irish it was essentially like being a secondary citizen. People used to put up signs saying 'No Irish' in the windows of boarding houses because there was such a stigma. Even though my dad has now moved over to Wales, he still has always remembered that simmering anti-Irish mentality from when he was younger, and he won't forget it because it was something so prevalent while he was growing up. So that was something you really made me think of when you said about there being so many different layers to any group of cultures or races of people when you have that 


\section{prefacing knowledge that other people may not be privy to. I'd never thought about it that way before.}

- And documenting is so important. It's not just the job of historians to speak to the generations who aren't there to find out these things. If you were to ask me about my experience of tumblr ten years ago, my memory is hazy but the importance of growing up on tumblr is still close to my heart - this is exactly what motivated my co-authors and I, who are all in our thirties, to write about tumblr because, how dare you tell us tumblr is dead now! We'll prove you wrong, right? I'm only half-joking! I think archiving something intangible like internet culture is all the more important, because much of it is transient and fleeting, and we overly rely on automation to self-archive. The knowledge of disappearing data is also a big motivation for us to quickly archive what we have taken for granted to be permanently online forever. Platforms close, websites shutdown, internet friends go away. I think we actually grapple with a lot of loss when we study internet cultures, and it can be a low-intensity, ongoing anxiety. But contributing to archiving and understanding something that is constantly disappearing and changing, while difficult to do, I think that can be very meaningful. 